\title{
The relationship between clinical audit and ethics
}

\author{
Sue Kinn Glasgow Caledonian University, Glasgow, Scotland*
}

\begin{abstract}
The aim of this paper is to start a debate about ethical issues associated with the practice of clinical audit. This is an area that has not received much consideration. The role of clinical audit is to raise general clinical standards. The ethical issues of clinical audit may have far-reaching consequences for clinicians, patients, health care providers and purchasers. Guidance is required to provide consistency in approach so that those involved in clinical audit, at whatever level, can be confident that they are following good practice. Clinicians and managers often think of good practice as being a technical matter. The main point of this paper is to bring out important ethical dimensions to good practice.
\end{abstract}

\section{Introduction}

Clinical audit was defined in the 1989 white paper, Working for Patients, ${ }^{1}$ as:

"The systematic critical analysis of the quality of care, including the procedures used for diagnosis and treatment, the use of resources and the resulting outcome and quality of life for the patient".

It is generally described as a cycle composed of several stages, the traditional audit cycle (figure 1). Put more simply it is a way of improving current performance by deciding on the ideal (setting standards), looking at the real situation (measuring current performance) and finding ways of moving from the real to the ideal (implementing change). Clinical audit is different from clinical research. Research is concerned with discovering the right thing to do; audit with ensuring that it is

\section{Author's note}

*Sue Kinn is funded by the Chief Scientist's Office, Scottish Office. All opinions expressed are those of the author, not necessarily those of the funding body.

\section{Key words}

Quality assurance; health care; clinical audit; clinical ethics done right. ${ }^{2}$ Differences between audit are research have been described ${ }^{3}{ }^{4}$ but there are many similarities between the two, including a systems atic, rigorous approach and a number of common methodologies. It is not always possible to identrity when a process ceases to be audit and becoms research, or vice versa. In the early days sonoe clinicians viewed audit as a way of doing "research on the cheap".

Clinical audit is a tool that can be used by ब्ब1 health care professionals (clinicians) to improve the care given to patients. The range of subjects being audited is vast and very many areas of work than have not been subjected to previous assessnent have come under scrutiny. Very often this has highlighted the lack of knowledge about a partic area, which in turn has stimulated further resear activity.

Many audits have now taken place; research hå shown that relatively high proportions of cliniciaz) have been involved. ${ }^{567}$ Much research activity ha् been expended in the evaluation of audit pra grammes and individual audit projects. ${ }^{8}$. However, as the process of audit matures othor aspects are emerging as needful of discussion, debate and research.

One such area that has arisen from clinicians, growing concerns is the ethical issues surroundiog clinical audit. Some authors have stated that there appears to have been wide acceptance that there are no ethical dimensions to audit. ${ }^{11}$ Howeve the process of audit does raise a number of issues

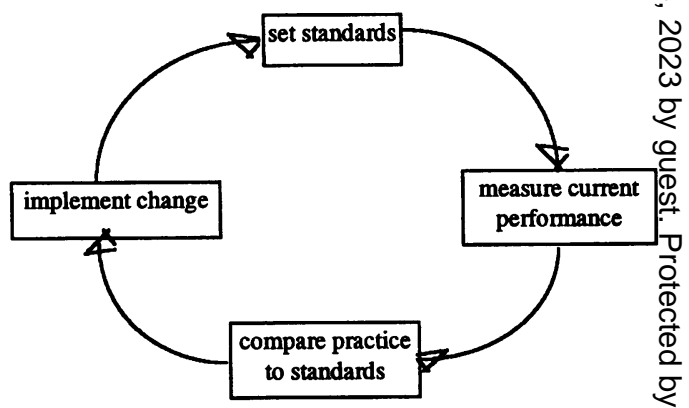

Figure 1. The traditional audit cycle 
These are:

- concerns around issues of confidentiality

- consent to use existing records

- the questioning of patients on potentially sensitive issues

- the use of scientifically valid methodology

- the involvement of local research ethics committees

- the problems arising from the need to publish

- duty to provide best possible care.

\section{Ethical considerations}

\section{CONFIDENTIALITY}

All health care professionals are bound by codes of confidentiality surrounding patient data. Data collected for audit are generally anonymised so that no conflict arises. However, under some circumstances (for example during ongoing data collection or when projects span some length of time) data that may identify individual patients or clinicians are held. This then raises issues about who should have access to these data.

The Thomson report ${ }^{13}$ was produced by a Scottish working group, set up to examine the relationship between clinical audit and management. It made recommendations concerning the rights and obligations of both clinicians and managers in the context of the relationship between clinical audit and management and commented upon other relevant issues. It was acknowledged that clinicians and managers had different perspectives on the purpose and achievements of clinical audit; the report aimed to reconcile these and to provide a workable solution.

The report provided clear guidance for levels of disclosure of information to participating clinicians, other colleagues, local managers and national interest groups in Scotland. It also recommended that the details of the results of audits should be shared by peers, with the prior agreement of those involved. Managers should have access to aggregated, anonymous data and there should be no way that a link could be made between the audit conclusions and named patients. To protect confidentiality in small units, the report recommended that these units should undertake joint projects

The report stressed that levels of reporting should be appropriate for local and national levels and that the purpose of audit was to be seen as a means of raising overall clinical standards and not as a threat.

This report would appear to have allayed, to some degree, the early concerns about confidentiality. A survey of doctors in the West of Scotland showed that the issues surrounding confidentiality were perceived as less of a barrier to performing audits than any other factor. ${ }^{14}$

\section{USE OF EXISTING DATA SOURCES}

Many audits review data that are already available from existing sources, such as clinical records, theatre log books and clinical information systems. Other audits may collect new data items, not routinely collected, on specially designed audit data collection sheets or questionnaires.

A report on the need for ethical review of studies using medical records, for the Royal College of Physicians, ${ }^{15}$ concluded that it is ethically acceptable, in principle, to use clinical records without approaching and involving the patients concerned, provided that confidentiality and anonymity are preserved. They stated that there is a duty to use available information for the general good where this can be done without detriment to anyone. They considered that medical audit was one of the activities that constitutes medical practice and as such does not require independent ethical review.

Other authors have said that ethical review is necessary under a number of different circumstances:

- all proposals for quality assurance programmes should be considered before accessing the data ${ }^{16}$

- where specific tools that have not been tested for reliability and validity are used ${ }^{11}$

- where work is externally sponsored and the prime reason is to meet the needs of the sponsor, not the practitioner $^{11}$

- where a third party is involved in collecting data ${ }^{11}$

- where confidentiality may be compromised. ${ }^{11}$

\section{QUESTIONING PATIENTS ON SENSITIVE ISSUES}

As audit develops and becomes increasingly sophisticated patients may become more involved in the process of audit. For instance they could be asked a number of potentially sensitive questions about their treatments, about the results of those treatments and about their feelings or attitudes to all aspects of the process of care. This might include questions about the effects of drugs, or other treatments, on the more personal aspects of a patient's life. The involvement of patients may change their expectations of the health care delivered and issues of clinical effectiveness and clinical acceptability must then be addressed in consultation with the patient. All of this has ethical implications. Current ethical guidelines for professional practice may not have sufficient in-depth discussion of the ethical issues involved in clinical audit (M Kenyon, Director Scottish Nursing Audit Development Project 1993-1996, personal communication). Anecdotal evidence (from a range of professions and health care settings) indicates that some studies are being carried out without prior approval and the staff involved feel vulnerable.

\section{USE OF SCIENTIFICALLY VALID METHODOLOGY}

Some form of audit has always been carried out by clinicians, but the more formal introduction of audit that has taken place recently has meant that more people are now involved, across all health professions and specialties. The high level of participation in audit ${ }^{567}$ and personal anecdotal evidence show 
that many audits are undertaken by clinicians who are not well versed in research methodologies, or who have not had any previous experience of research and the associated ethical issues. It has just been taken for granted that they will be able to devise and/or use audit methodologies. But if the methods used are not scientifically valid then this will have important ethical implications. This raises issues to do with the need for training in rigorous research and audit methodologies for all clinicians and the need for regular review and evaluation of local audit activities. There is a general recognition that there is a need for training in many non-clinical areas to make audit effective. ${ }^{14}$ As individuals become more experienced the process should become better organised but this is an area that must be examined and any problems identified rectified, for ethical reasons as much as for efficiency.

\section{INVOLVEMENT OF LOCAL RESEARCH ETHICS COMMITTEES}

There is a complex network of Local Research Ethics Committees (LRECs), which was set up to review research proposals. All health care providers would agree, if asked, that there is an unwritten acceptance that all audit must also be ethically acceptable. But this does not mean in practice that LRECs are invariably involved. Amongst the different trusts and health boards, it seems, a mixture of solutions involving LRECs have evolved. Historically, some at first required ethical committee approval for all audits, whilst others were not involved in consideration of any audit projects. This situation has settled down now and each trust has its own working solutions. However, these do vary, creating confusion as clinicians move between trusts. The result can be that clinicians and trusts not used to the issues surrounding ethical approval may embark upon projects where required approval is not sought. Additionally, in an increasing number of cross-boundary or interface audits there there may be some debate about which ethical committees should be involved.

The literature in this area is very small and not sufficiently detailed to allow clear guidance. ${ }^{11} 1516$ There is, however, an increasing need to identify possible problem areas and for the production of clear guidance for those embarking upon audit, to ensure consistency in approach. This should safeguard patients and practitioners so that those involved in audit, at whatever level, do not feel exposed or vulnerable.

\section{PUBLICATION}

Other problems arise when there is a wish to publish a successful audit, as many professional journals will not publish articles unless they are accompanied by evidence of ethical committee approval. ${ }^{17}$ This sort of stricture can restrict audit activity if junior members of staff, mindful of the need to publish to progress along the career ladder, do not take part in audinos. Clear guidance on when to seek LREC approval câp clarify the position for clinical and editorial staff, thits allowing audit reports to be published.

PROVISION OF BEST POSSIBLE CARE

All health care professionals have a responsibility provide the best possible care, which could be int preted to mean that not to be involved in audit is a breach of the ethical code of conduct. The ethical area of audit could therefore have far-reaching consequences for all clinicians and needs to be explored in more depth.

\section{Some problems}

The role of clinical audit is to raise general clinióal standards and from its introduction it has been seen as an educational exercise. ${ }^{18} 19$ If clinical auditinj seen as threatening, for instance if it is seen as a way of monitoring the progress of an individual, it wall not be carried out willingly or accurately.

Managers need to look at the results of audit seriously, to ensure the best possible use of resoures delivers the best quality care possible. This kind scrutiny clearly overlaps with organisational azुd business planning since trusts, or other health providers, have responsibilities for providing serơंics and using resources. It also has implications for purchasers of the services, who wish to buy hon care of a certain quality.

Clinical audit should be part of an integrated p gramme of quality assurance (as part of the overall strategy of the provider) aimed at showing that the is an improvement in the quality of the care given to patients, not just that audit is going on. Occasiona audits indicate the need for change and are not acted upon. This could be due to inaction by the clinicians or the clinical team or to the lack of resources mage available by the provider (time, staff, equipment, costs, etc) to implement the changes. Inaction of this kind has far-reaching consequences in terms both $\equiv$ of professional codes of conduct and of business censtraints of trusts or other health care providers.

What sanctions should there be if clinicians $\frac{D}{\text { or }}$ managers fail to heed the results of clinical aug fit projects where the need for change and impropement in the care provided is clearly demonstrated? Will publishing the results of audits, to a wider audience, have any effect on clinical practice?

As evidence is made increasingly more accessibु్, in a variety of formats, patients will become more informed, and increasingly involved in the decisions about clinical care and the process of clinical audit and outcomes. ${ }^{20}$ Such involvement is to be comed but must be introduced in a sensible and se sitive manner. Clear guidance about ethical aspecots of the involvement of patients is required if patient and professional anonymity and confidentiality are to be maintained. 


\section{Conclusion}

This paper is intended to stimulate discussion which will lead to the exploration of different ethical issues that may impact upon the process of clinical audit. Individuals and organisations have their own solutions to some of these issues, and these need to be brought to the attention of others and discussed, so that good practice can be identified. If best practice is to be promoted all clinical audit must be based on sound and publicly accepted ethical principles.

\section{Acknowledgements}

I would like to thank Professor Robin Downie of Glasgow University, for his help and encouragement.

Sue Kinn, BSc, MSc, PhD, is Project Leader at the Nursing Research Initiative for Scotland, Glasgow Caledonian University, Glasgow.

\section{References}

1 Department of Health. Working for patients - medical audit. Scottish working paper 2. London: HMSO, 1989.

2 Smith R. Audit and research. British Medical fournal 1992; 305: 905-6.

3 Madden AP. Research or audit. Network 1991; 1 : 1.

4 Kauder A. Audit and clinical research. In: Thomson TJ, ed. The interface between clinical audit and management. Edinburgh: Clinical Resource and Audit Group, 1993.

5 Firth-Cozens J, Storer D. Registrars' and senior registrars' perceptions of their audit activities. Quality in Health Care 1992; 1: 161-4.

6 Pringle M, Bradley C, Carmichael C, Wallis H, Moore AA. Survey of attitudes to and experience of medical audit in general practice: implications for MAAGs. Audit trends 1994; 2: 9-13.
7 Kinn SR, Smith PJ. Medical audit activity in primary and secondary care in the West of Scotland. Health Bulletin 1996; 54: 252-7.

8 Walshe K, Coles J. Evaluating audit: developing a framework. London: CASPE Research, 1993.

9 Walshe K, Coles J. Evaluating audit: a review of initiatives. London: CASPE Research, 1993.

10 Baker R, Hearnshaw H, Cooper A, Cheater F, Roberston N. Assessing the work of medical audit advisory groups in promoting audit in general practice. Quality in Health Care 1995; 4: 234-9.

11 Rix G, Cutting K. Clinical audit, the case for ethical scrutiny? International fournal of Health Care Quality Assurance 1996; 9/6: 18-20

12 British Medical Association. Clinical Audit Committee. Ethical issues in audit. London: British Medical Association, 1995.

13 Thomson TJ. The interface between clinical audit and management. Edinburgh: Clinical Resource and Audit Group, 1993.

14 Smith PJ, Kinn SR. Learning to avoid frustrations with audit. Audit Trends 1995; 3: 53-6.

15 Working group of the Royal College of Physicians' committee on ethical issues in medicine. Independent ethical review of studies involving personal medical records. Fournal of the Royal College of Physicians of London 1994; 28: 439-43.

16 Koschnitzke L, McCracken SC, Pranulis MF. Issues in clinical nursing research: ethical considerations for quality assurance versus scientific research. Western fournal of Nursing Research 1992; 14: 392-6.

17 Madhok R. Audit and research. Lancet 1992; 340: 1103-4.

18 Standing Committee on Postgraduate Medical Education (SCOPME). Medical audit: the educational implications. London: SCOPME, 1989.

19 Coles C. Making audit truly educational. Postgraduate Medical fournal 1990; 66(supp3): S32-S36.

20 Kelson M. Consumer involvement initiatives in clinical audit and outcomes: a review of developments and issues in the identifications of good practice. London: College of Health, 1995. 